The original publication is available at http://www.nature.com

\title{
Influence of the state of the Indian Ocean Dipole on the following year's El Niño
}

Takeshi Izumo $^{1,2,6,{ }^{*} \text {, Jérôme Vialard }}{ }^{3}$, Matthieu Lengaigne ${ }^{3}$, Clément de Boyer Montegut $^{1,4}$, Swadhin K. Behera ${ }^{1}$, Jing-Jia Luo ${ }^{1}$, Sophie Cravatte ${ }^{5}$, Sébastien Masson ${ }^{3}$ \& Toshio Yamagata ${ }^{1,2}$

${ }^{1}$ Research Institute for Global Change, JAMSTEC, Yokohama 236-0001, Japan

${ }^{2}$ University of Tokyo, Tokyo 113-0033, Japan

${ }^{3}$ LOCEAN, IRD-CNRS-UPMC, Paris 75252, France

${ }^{4}$ LOS, IFREMER, Brest 29280, France

${ }^{5}$ LEGOS, IRD-CNRS-UPS, Toulouse 31400, France

${ }^{6}$ Present address: Ocean and Atmosphere Group, Department of Earth and Planetary Sciences, Graduate School of Science, The University of Tokyo, Hongo 7-3-1, Bunkyo-ku, Tokyo 113-0033, Japan

*: Corresponding author : Takeshi Izumo, email address : izumo@jamstec.go.jp

\begin{abstract}
:
El Niño-Southern Oscillation (ENSO) consists of irregular episodes of warm El Niño and cold La Niña conditions in the tropical Pacific Ocean ${ }^{1}$, with significant global socio-economic and environmental impacts ${ }^{1}$. Nevertheless, forecasting ENSO at lead times longer than a few months remains a challenge $^{2,3}$. Like the Pacific Ocean, the Indian Ocean also shows interannual climate fluctuations, which are known as the Indian Ocean Dipole ${ }^{4,5}$. Positive phases of the Indian Ocean Dipole tend to co-occur with El Niño, and negative phases with La Niña ${ }^{6,7,8,9}$. Here we show using a simple forecast model that in addition to this link, a negative phase of the Indian Ocean Dipole anomaly is an efficient predictor of El Niño 14 months before its peak, and similarly, a positive phase in the Indian Ocean Dipole often precedes La Niña. Observations and model analyses suggest that the Indian Ocean Dipole modulates the strength of the Walker circulation in autumn. The quick demise of the Indian Ocean Dipole anomaly in November-December then induces a sudden collapse of anomalous zonal winds over the Pacific Ocean, which leads to the development of El Niño/La Niña. Our study suggests that improvements in the observing system in the Indian Ocean region and better simulations of its interannual climate variability will benefit ENSO forecasts.
\end{abstract}


The feasibility and limits of ENSO forecasts are grounded in our knowledge of ENSO physics. An El Niño develops as the result of the Bjerknes feedback, a positive ocean-atmosphere interaction that links the strength of easterlies to sea surface temperature (SST) in the central Pacific ${ }^{11}$. A warm anomaly in the central Pacific induces an eastward displacement of the atmospheric deep convection, and westerly wind anomalies in the central and western Pacific. This westerly wind anomaly drives an ocean response that reinforces the initial SST anomaly. This positive feedback loop eventually leads to an El Niño event, typically culminating in boreal winter. While this simple instability mechanism does not allow for any predictability, ocean dynamics can provide a "memory" for ENSO ${ }^{12}$. The equatorial Pacific Warm Water Volume (WWV, volume of water above $20^{\circ} \mathrm{C}$ within $5^{\circ} \mathrm{N}-5^{\circ} \mathrm{S}, 120^{\circ} \mathrm{E}-80^{\circ} \mathrm{W}$ ) is an essential parameter in the ENSO cycle ${ }^{13}$. The "recharge oscillator" model of ENSO ${ }^{14}$ 
provides a simple physical explanation: the WWV controls temperature of water upwelled in the equatorial Pacific; a high WWV favours a warm anomaly, leading to an El Niño via the Bjerknes feedback. The zonal wind anomalies during an El Niño then induce a zonal pressure gradient that tends to chase warm water away from the equatorial strip, inducing negative WWV anomalies after the El Niño peak and a transition to La Niña.

The IOD is the Indian Ocean equivalent of ENSO. During a positive IOD, anomalously low SSTs appear off Sumatra in summer, inducing weaker local convection and easterly wind anomalies, further increasing the initial SST anomalies through the Bjerknes feedback. The IOD peaks in October and then quickly recedes. The IOD is an intrinsic mode of variability of the Indian Ocean, but has a tendency to occur synchronously with ENSO ${ }^{6,7}$ (cf. the significant 0.6 correlation at zero-lag in Fig. 1a). Numerous studies have investigated the interactions between simultaneous ENSO and IOD events: El Niño conditions favour the development of a positive IOD by increasing easterly wind off Sumatra in summer ${ }^{15}$ and it has been suggested that this positive IOD could in turn retroact on El Niño ${ }^{6,7,8,9}$.

Our results demonstrate that IOD events not only tend to co-occur with ENSO events but also to lead them (cf. the significant -0.5 correlation at one year lead in Fig. 1a). Negative (positive) IODs tend to precede the development of El Niño (La Niña) events, while ENSO has no significant predictive skill of the IOD at one-year lead (Fig. 1a and composite analyses in supplementary information). To assess the potential influence of IOD state on ENSO onset, we have constructed a bilinear regression model of ENSO combining WWV and an IOD index. Most statistical forecasts of ENSO use predictors from the tropical Pacific Ocean ${ }^{2}$. In agreement with the "recharge oscillator" theory, the observed WWV provides an efficient predictor of the ENSO peak up to 8 months in advance ${ }^{13,16}$. However, WWV alone is not sufficient to predict ENSO peak before the winter-spring "predictability barrier", ${ }^{, 3}$ (Fig. 1b). As westerly wind anomalies in the western Pacific are also important for El Niño development ${ }^{1,12,17,18,19}$, a usual approach is to combine them with $\mathrm{WWV}^{2}$. This allows to 
hindcast the ENSO peak with a skill score above 0.75 when starting from late spring (February-April, i.e. a lead of 8 months, Fig. 1b). An equivalent score can be obtained at a longer lead of 13-15 months by combining WWV with the Dipole Mode Index $^{4}$ in September-November (Fig. 1b). This corresponds to a backward extension of the 0.75 skill score limit of 6 months, and to a large and statistically significant improvement of the score. In combination with the simple lag-correlation analysis of Fig. 1a, this is a strong suggestion of the influence of the IOD phase on following year's El Niño / La Niña. Using IOD information for example improves forecasts of the large 1982-83 and 1997-98 El Niños, whereas WWV-only forecasts predicted near-neutral conditions (Figs 2b,c). The hindcasts also perform well for ENSO at developing stage (Fig. 1b). The hindcast performance is robust: it is neither significantly degraded when the regression model is trained on one half of the period, nor when the two strongest El Niño events (1982-83 and 1997-98) are removed (Table 1). The performance of the hindcasts can be further improved by using an IOD index based on atmospheric deep convection (and hence more directly linked to the Walker circulation) rather than the classical dipole mode index ${ }^{4}$ (see Table 1 and Supplementary Information).

Whereas influence of Indian Ocean variables on ENSO predictability has been suggested before ${ }^{17,20,21}$, the present study clearly identifies the IOD as an important precursor of ENSO. It provides a skill score of 0.8 beyond one year of lead-time, higher than scores obtained with previous statistical ${ }^{2}$ and dynamical ${ }^{3}$ models (Supplementary Figure S4). It highlights that the Indian Ocean is not completely enslaved to the powerful ENSO cycle from the neighbouring Pacific: it has degrees of freedom on its own and even partially controls ENSO state the following year. The bilinear regression normalised coefficients of the IOD index (-0.85) and WWV (0.69) to the normalized ENSO index suggest an equivalent importance of the IOD external forcing and Pacific heat content on ENSO at one-year lead.

Observations and model analyses give insights on the mechanism responsible for the 
influence of IOD phase on subsequent year's ENSO conditions, discussed here for the case of El Niño development. Fig. 2 shows the observed Indo-Pacific signature of a negative IOD (the synchronous ENSO influence has been regressed out, see Methods). During a negative IOD, the southeast Indian Ocean experiences a warming peaking in October (Fig. 2a). At the time of the IOD peak, the western and central Pacific also experiences increased easterly winds (Fig. 2c). These easterly anomalies favour the buildup of $\mathrm{WWV}^{12,14,17,18}$ in the western Pacific (Fig. 2b), providing an efficient preconditioning for El Niño to develop. After November, the eastern pole of the IOD quickly recedes ${ }^{4}$ (Figs 2a,b). This induces a quick collapse of anomalous easterlies in the central Pacific (Fig. 2c) followed by El Niño development (Figs 2a-c).

To investigate the remote influence of IOD anomalies on the tropical Pacific, we have analysed a coupled general circulation model (CGCM) experiment where coupling is active over the Indian Ocean but not over the Pacific Ocean (see Methods). This experiment confirms that increased convection in the eastern Indian Ocean induces a speedup of the Walker circulation (easterly anomalies over the Pacific Ocean, and westerly wind anomalies over the Indian Ocean) during fall (Fig. 2d). The oceanic response over the following months can be analysed in a simple shallow-water model experiment (see Methods). Easterly anomalies in September forces an upwelling Kelvin wave and a downwelling Rossby wave, first generating cold anomalies in the eastern Pacific, as in observations (Figs 2-3). These waves reflect at both boundaries and constructively interact with waves of opposite sign generated in the central Pacific by the abrupt collapse of the easterly anomalies in early winter. This leads to eastward zonal current anomalies around the dateline in winter and spring, inducing eastward advection of the warm pool ${ }^{10}$ and warm SST anomalies (Fig. 3). From February-March onward, air-sea coupling starts amplifying the SST and wind anomalies through the Bjerknes feedback (Figs 2a,c), eventually leading to El Niño development. Our analyses therefore suggest a mechanism similar to the advective- 
reflective ${ }^{10}$ conceptual model of ENSO, but in response to IOD-driven easterly anomalies and their abrupt relaxation.

Numerous studies have illustrated the potential impact of winter-spring intraseasonal wind anomalies in the western Pacific on El Niño development ${ }^{16,17,22,23}$. These anomalies include the Madden-Julian Oscillation ${ }^{24}$ (MJO) at periods of 30-100 days and westerly wind bursts $^{17,23}$ (WWBs) at higher frequency. The detailed evolution of WWBs and MJO cannot be predicted beyond a couple of weeks. This sounds at odds with the present study, which shows that ENSO is highly predictable as far as 18 months in advance (Fig. 1b). This can be understood in the context of the mechanism proposed above. Previous studies have shown that intraseasonal wind variability is modulated by western Pacific low-level westerlies and warm pool extension ${ }^{24,25,26}$. The IOD-induced winter-spring eastward displacement of the warm pool hence results in an increase of intraseasonal variability ${ }^{27}$, as demonstrated by Fig. 4. The IOD index thus contains information on both interannual wind anomalies in the western-central Pacific (Fig. 2c) and modulation of intraseasonal wind activity that precede El Niños ${ }^{16,24}$. This change in intraseasonal wind variability in the western Pacific could contribute to El Niño growth ${ }^{16,22,23}$ together with the lower frequency wind anomaly.

Combining IOD and WWV influences pushes the 0.8 skill score limit of ENSO backward in time, 13-15 months before the ENSO peak. This increased predictability stems from the partial independence of the Indian Ocean from the Pacific Ocean. The paradigm proposed here also suggests a possible explanation for the biennial tendency of $\mathrm{IOD}^{4}$ and $\mathrm{ENSO}^{28}$ : a negative IOD tends to induce an El Niño the following year, which is often associated with a positive IOD favouring a subsequent La Niña. This seems to be confirmed by coupled model experiments, which display a diminished biennial tendency for ENSO when climatological conditions are specified in the Indian Ocean ${ }^{8,28}$.

Previous studies have underlined a possible interdecadal change of teleconnections 
between ENSO and the Indian Ocean ${ }^{7}$. Repeating the hindcast exercise of Figure 1 before 1980 is difficult, because reliable WWV data is then unavailable. It is hence difficult to explore the interdecadal stability of the IOD influence on following year's ENSO in observations. The simple correlation between the IOD and following year's ENSO computed using several indices and datasets (Supplementary Table S1) is consistently somewhat lower prior to $1980(-0.31$ to -0.41$)$ than for $1981-2008(-0.48$ to -0.55$)$. This might be due to changes in the observational system (Supplementary Analysis 2.4a), and also to interdecadal fluctuations of the IOD influence on following year's ENSO. Analyses of a long CGCM experiment suggest clear interdecadal fluctuations of the relative influences of IOD phase and WWV on following year's ENSO state (Supplementary Analysis 2.4b). Although the IOD influence on following year's ENSO was strong for the recent period, it may hence have also experienced some interdecadal fluctuations.

This study claims for a better understanding of links between the Indian and Pacific oceans. This is a necessary step to delineate the necessary physics to resolve in coupled ocean-atmosphere forecasting systems, which eventually represent the most complete way forward for seasonal forecasting. Integrating present results within such forecasting systems could push ENSO predictability further ahead, as the IOD and WWV can be forecasted one to two seasons in advance ${ }^{29}$. For achieving this improved understanding and a better constraint on dynamical forecasting systems, a necessary step forward is the achievement of a similar observing system in the Indian Ocean as those already established in the tropical Pacific and Atlantic oceans ${ }^{30}$. 


\section{Methods}

Observations (see detailed description and references in supplementary material). The observational analysis uses mostly NOAA OISST V2 in situ/satellite data product (available from November 1981), NOAA interpolated OLR, zonal wind (at $10 \mathrm{~m}$ ) and wind stress from NCEP2 reanalysis, average 0-300m oceanic temperature from CERFACS ENSEMBLES reanalysis, and finally observed WWV of the equatorial Pacific ${ }^{13}$.

ENSO and IOD indices. We use classical ENSO and IOD indices. The ENSO index is based on the SST anomalies averaged in the Niño3.4 region $\left(170^{\circ} \mathrm{W}\right.$ to $120^{\circ} \mathrm{W}, 5^{\circ} \mathrm{S}$ to $\left.5^{\circ} \mathrm{N}\right)$. The "Dipole Mode Index" (DMI $)^{4}$ is based on the SST anomalies in $50^{\circ} \mathrm{E}-70^{\circ} \mathrm{E}, 10^{\circ} \mathrm{S}-10^{\circ} \mathrm{N}$ minus those in $90^{\circ} \mathrm{E}-110^{\circ} \mathrm{E}, 10^{\circ} \mathrm{S}-0^{\circ} \mathrm{N}$. Both indices (named "IOD" and "ENSO" below) are normalized. The definition of the "peak" is September-November for the IOD and OctoberDecember for ENSO (using December-February for ENSO gives similar results).

Statistical analyses. Statistical analyses and hindcasts are performed over September 1981 to February 2009. The hindcasts of Niño3.4 SST 3-months averages in Fig. 1 are performed using predictors either from September-November (fall) or from February-April (spring). Significances are computed using Student t-test (other more elaborate significance tests give similar results). Figs $2 \mathrm{a}-\mathrm{c}$ and 4 extract the influence of the IOD on the tropical Pacific by removing the ENSO contribution. Variables Y (wind, SST, etc...) are bilinearly regressed to non-dimensional IOD and ENSO peak indices $(Y=a * I O D+b * E N S O+\varepsilon)$. The linear regression coefficient $a$ is then plotted, with a minus sign to illustrate the negative IOD case. For Figure 4, the amplitude of wind stress variability during each winter (December-March) is estimated using the standard deviation of the 30-100 day band-passed filtered wind stress, and the resulting field is then linearly regressed to the IOD index.

Models. In Fig. 2d, we use the SINTEX-F $\mathrm{CGCM}^{29}$ to investigate the signature of the IOD over the Pacific Ocean. In this specific simulation, the SST over the Pacific is constrained to 
the coupled model climatology in order to "switch-off" coupling over the Pacific Ocean. As a result, ENSO is absent from this simulation and Pacific Ocean signals only result from atmospheric teleconnections. In Figure 3, we have used a shallow water model to investigate the oceanic response to the IOD-external forcing, represented as a Gaussian wind patch (centered at $0^{\circ} \mathrm{N}, 170^{\circ} \mathrm{E}$, with e-folding widths of $30^{\circ}$ in longitude and $7.5^{\circ}$ in latitude, and

maximal amplitude of $-0.01 \mathrm{~N} \mathrm{~m}^{-2}$ ) applied from September to November. A simple SST equation including advection of climatological SST gradients by the shallow water currents and thermocline effects allows estimating the SST anomalies. The CGCM and shallow water models are described in more details in the supplementary material.

A summarizing sketch of the main mechanism and several additional analyses are provided in Supplementary Information. 


\section{References}

1. McPhaden, M.J., S.E. Zebiak, \& M.H. Glantz. ENSO as an integrating concept in Earth science. Science 314, 1740-1745 (2006).

2. Barnston, A. G., M. H. Glantz, \& Y. He. Predictive skill of statistical and dynamical climate models in SST forecasts during the 1997-98 El Niño Episode and the 1998 La Niña Onset. Bull. Amer. Meteor. Soc., 80, 217-243 (1999).

3. Jin E. K., James L. Kinter III, B. Wang, C.-K. Park, I.-S. Kang, B. P. Kirtman, J.S. Kug, A. Kumar, J.-J. Luo, J. Schemm, J. Shukla, \& T. Yamagata. Current status of ENSO prediction skill in coupled ocean-atmosphere models. Clim. Dyn., 31, 647-664 (2008).

4. Saji, N. H., B. N. Goswami, P. N. Vinayachandran \& T. Yamagata. A dipole mode in the tropical Indian Ocean. Nature, 401, 360-363 (1999).

5. Webster, P. J., A. M. Moore, J. P. Loschnigg, \& R. R. Leben. Coupled oceanicatmospheric dynamics in the Indian Ocean during 1997-98. Nature, 401, 356-360 (1999).

6. Yamagata, T., S. K. Behera, J.J. Luo, S. Masson, M. R. Jury, \& S. A. Rao. Coupled Ocean-Atmosphere variability in the Tropical Indian Ocean, in Earth climate: The Ocean-Atmosphere Interaction. Geophys. Monogr. Ser., 147, AGU, Washington, D. C. (2004).

7. Annamalai, H., S.-P. Xie, J.-P. McCreary, \& R. Murtugudde. Impact of Indian Ocean sea surface temperature on developing El Niño. J. Clim., 18, 302-319 (2005). 
8. Behera, S. K., J.J. Luo, S. Masson, S. A. Rao, H. Sakuma \& T. Yamagata. A CGCM study on the interaction between IOD and ENSO, J. Clim., 19, 1608-1705 (2006).

9. Luo, J.-J., R. Zhang, S. K. Behera, Y. Masumoto, F.-F. Jin, R. Lukas, \& T. Yamagata, Interaction between El Nino and Extreme Indian Ocean Dipole. $J$. Clim., in press (available at http://www.jamstec.go.jp/frcgc/research/d1/iod/2007/forecast/Luoetal.ENSOIOD.JCLI09.pdf ) (2009).

10. Picaut, J., F. Masia, \& Y. du Penhoat, An advective-reflective conceptual model for the oscillatory nature of the ENSO, Science, 277, 663-666 (1997).

11. Bjerknes, J. A possible response of the atmospheric Hadley circulation to anomalies of ocean temperature. Tellus, 18, 820-829 (1966).

12. Wyrtki, K., Water displacements in the Pacific and the genesis of El Niño cycles. J. Geophys. Res., 90, 7129-7132 (1985).

13. Meinen, C.S. \& M.J. McPhaden, Observations of warm water volume changes in the equatorial Pacific and their relationship to El Niño and La Niña. J. Clim., 13, $3551-3559$ (2000).

14. Jin, F.-F., An equatorial ocean recharge paradigm for ENSO. Part I: Conceptual model. J. Atmos. Sci., 54, 811-829 (1997).

15. Annamalai, H., R. Murtugudde, J. Potemra, S.P. Xie, P. Liu, \& B. Wang, Coupled dynamics over the Indian Ocean: Spring initiation of the zonal mode. Deep Sea Research II, 50, 2305-2330 (2003). 
16. McPhaden, M.J., X. Zhang, H.H. Hendon, \& M.C. Wheeler, Large Scale Dynamics and MJO Forcing of ENSO Variability. Geophys. Res. Lett., 33(16), L16702, doi:10.1029/2006GL026786 (2006).

17. Yamagata T. and Matsumoto Y. A simple ocean-atmosphere coupled model of the origin of a warm ENSO event. Phil. Trans. R. Soc. Lond. A, 329, 225-236 (1989).

18. Wang, C., R. H. Weisberg, \& J. I. Virmani, Western Pacific interannual variability associated with the El Niño-Southern Oscillation, J. Geophys. Res., 104, 51315149 (1999).

19. Kug J.-S., \& I.-S. Kang: Interactive Feedback between ENSO and the Indian Ocean. J. Climate, 19, 1784-1801 (2006).

20. Clarke, A. J., S. Van Gorder, Improving El Niño prediction using a space-time integration of Indo-Pacific winds and equatorial Pacific upper ocean heat content, Geophys. Res. Lett., 30(7), 1399, doi:10.1029/2002GL016673, (2003).

21. Webster, P. J.,The annual cycle and the predictability of the tropical coupled ocean-atmosphere system. Meteor. Atmos. Phys., 56, 33-55 (1995).

22. Kessler, W. S., M. J. McPhaden, \& K. M. Weikmann, Forcing of intraseasonal Kelvin waves in the equatorial Pacific, J. Geophys. Res., 100, 10,613-10,631 (1995).

23. Lengaigne, M., J.-P. Boulanger, C. Menkes, P. Delecluse, \& J. Slingo, Westerly wind events in the tropical Pacific and their influence on the coupled oceanatmosphere system: A review, in Earth Climate: The Ocean-Atmosphere Interaction, Geophys. Monogr. Ser., 147, 49- 69, AGU, Washington, D. C. (2004).

24. Zhang, C., Madden-Julian Oscillation, Rev. Geophys., 43, RG2003, doi:10.1029/2004RG000158 (2005). 
25. Seiki, A., \& Y.N. Takayabu, Westerly Wind Bursts and Their Relationship with Intraseasonal Variations and ENSO. Part I: Statistics. Mon. Wea. Rev., 135, 33253345 (2007).

26. Eisenman, I., L. Yu, \& E. Tziperman, Westerly wind bursts: ENSO's tail rather than the dog? J. Climate, 18, 5224-5238 (2005).

27. Izumo, T., Masson S., Vialard J., C. de Boyer Montegut, S. K. Behera, G. Madec, K. Takahashi \& T. Yamagata. Low and high frequency Madden-Julian Oscillations in Austral Summer - Interannual variations. Clim. Dyn., in press, published online (2010).

28. Yu, J.-Y., Enhancement of ENSO's persistence barrier by biennial variability in a coupled atmosphere-ocean general circulation model, Geophys. Res. Lett., 32, L13707, doi:10.1029/2005GL023406 (2005).

29. Luo, J.-J., S. Masson, S. Behera, \& T. Yamagata, Experimental Forecasts of the Indian Ocean Dipole Using a Coupled OAGCM, J. Clim., 20, 2178-2190 (2007).

30. McPhaden, M.J., G. Meyers, K. Ando,Y. Masumoto, V.S.N. Murty, M. Ravichandran, F. Syamsudin, J. Vialard, L. Yu, \& W. Yu, RAMA: The Research Moored Array for African-Asian-Australian Monsoon Analysis and Prediction. Bull. Am. Meteorol. Soc., 90, 459-480 (2009). 
Acknowledgments The first author would like to dedicate this study to his $\mathrm{PhD}$ advisor, Dr. Joel Picaut, who inspired him with knowledge and enthusiasm. PJ. Webster and two anonymous reviewers provided constructive comments, which helped us in improving an earlier version of the manuscript. We would like to thank JAMSTEC/RIGC and NIO (India) for their support and hospitality, and NOAA/PMEL for making TAO data and the FERRET analysis tool available. This work was funded by JSPS, IRD, the University of Tokyo and IRD/CNRS

Author contributions T.I. performed most of the analyses in this paper, with support and advices from J.V. and M.L. T.I., J.V. and M. L. wrote most of the text of the paper. C.d.B.M. helped in collecting the data. S.K.B provided the shallow water model. J.-J.L. performed the SINTEX-F model experiments and hindcasts. All the authors contributed to the material in this paper through numerous discussions.

Correspondence and requests for materials should be addressed to T.I.

(izumo@jamstec.go.jp). 


\section{Figures captions and tables}

Fig. 1: IOD index as a precursor of following year's ENSO state. a) Lag-correlation between IOD (in Sept-Nov of year 0) and ENSO indices (dashed lines indicate the 95\% confidence limit). b) Correlation skill of Niño3.4 SST hindcasts using WWV and western Pacific zonal wind in Feb-Apr of year 1 (black), using only WWV in Sept-Nov of year 0 (blue), or WWV + IOD index in Sept-Nov of year 0 (red). c) Observed (black) and predicted (red) ENSO index using the WWV and IOD indices of Sept-Nov 13 months before. d) black curve as in c; the hindcast in c is the sum of the WWV (blue) and DMI (purple) contributions.

Fig. 2: Longitude-time section of Indo-Pacific anomalies associated with a negative IOD.

a) Observed $\operatorname{SST}\left({ }^{\circ} \mathrm{C}\right)$, b) $0-300 \mathrm{~m}$ oceanic temperature $\left.\left({ }^{\circ} \mathrm{C}\right), \mathrm{c}\right)$ zonal wind $\left(\mathrm{m} \mathrm{s}^{-1}\right)$ over the Indo-Pacific during and after a negative IOD event (the influence of ENSO has been removed, see Methods). d) Indo-Pacific zonal wind signals associated with the IOD in a coupled model experiment with no coupling over the tropical Pacific. Signals are within $2^{\circ} \mathrm{S}-$ $2^{\circ} \mathrm{N}$, except for SST (within $5^{\circ} \mathrm{S}-5^{\circ} \mathrm{N}$ in the Pacific, and $10^{\circ} \mathrm{S}-0^{\circ} \mathrm{N}$ to the west of $120^{\circ} \mathrm{E}$ ). Only signals significant at the $90 \%$ level are plotted. 
Fig 3. Longitude-time diagram of equatorial $\left(2^{\circ} \mathrm{S}-2^{\circ} \mathrm{N}\right)$ Pacific response to the IOD external forcing, as estimated from shallow water model experiment. a) Thermocline depth (contours, with negative values dashed) and SST (colours) anomalies. The arrows indicate the period at which the wind stress perturbation corresponding to IOD external forcing has been applied. b) Zonal current anomalies (colours). The Kelvin and Rossby wave response is indicated by thin black arrows (continuous line for downwelling and dashed for upwelling waves). The resulting zonal current perturbations are indicated by blue (westward) and red (eastward) arrows.

Fig. 4: Intraseasonal zonal wind stress variations in the Western Pacific in DecemberMarch after a negative IOD. Standard deviation of 30-100 days bandpass filtered zonal wind stress in DJFM partially regressed on IOD index, with ENSO influence removed $\left(10^{-3}\right.$ $\mathrm{N} \mathrm{m}^{-2}, 90 \%$ significance level in black contours). 


\section{Table 1}

\begin{tabular}{|c|c|c|c|}
\hline Predictors & $\begin{array}{l}\text { Hindcast corr. } \\
\text { skill (rms error) }\end{array}$ & $\begin{array}{l}\text { Simple } \\
\text { correlation }\end{array}$ & $\begin{array}{l}\text { Cross-validated } \\
\text { score }\end{array}$ \\
\hline $\begin{array}{l}\text { Sep.1981-Dec.2008 (27 years), using } \\
\text { DMI+WWV }\end{array}$ & $0.82(0.69)$ & -0.54 & $0.79(0.73)$ \\
\hline OLR index in Oct. instead of DMI & $0.87(0.58)$ & -0.65 & $0.84(0.64)$ \\
\hline Niño3.4 SST instead of DMI & $0.59(0.96)$ & -0.16 & $0.52(1.01)$ \\
\hline $\begin{array}{l}\text { Skill when the } 1982 \text { and } 1997 \mathrm{El} \\
\text { Niños are excluded }\end{array}$ & $0.79(0.62)$ & -0.47 & $0.75(0.67)$ \\
\hline $\begin{array}{l}\text { Hindcast Sep.1981-Dec.1993 } \\
\text { years, training period: 1994-2008) }\end{array}$ & $0.80(0.72)$ & & \\
\hline $\begin{array}{l}\text { Hindcast } \quad \text { Sep.1996-Dec.2008 } \\
\text { years, training period 1981-1995) }\end{array}$ & $0.85(0.65)$ & & \\
\hline
\end{tabular}

Table 1. Skill and robustness of the IOD index as a predictor of ENSO. First column: correlation skill (and root mean square error) of bilinear hindcasts of ENSO index using 13 month lead WWV and various indices, whose correlation to following year's ENSO index is given in the second column. The last column gives scores obtained when omitting the target year in the bilinear model training. The first three lines are respectively for: the standard hindcast we use in this paper; the "best" predictor based on an atmospheric convection (OLR) IOD inde ${ }^{27}$ and WWV in October; and Niño3.4 SST. The last three lines show the stability of the scores when some years are excluded. 
a) lag-correlation between IOD and ENSO

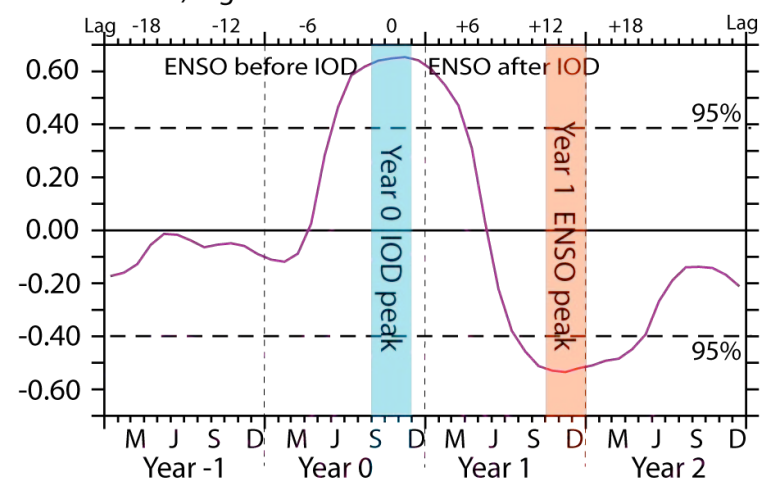

b) correlation skill of various ENSO hindcasts

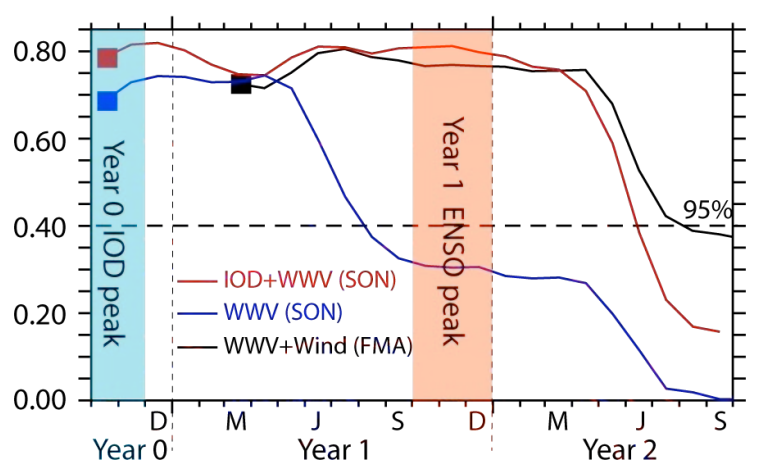

c) ENSO hindcast at 13-15 month lead

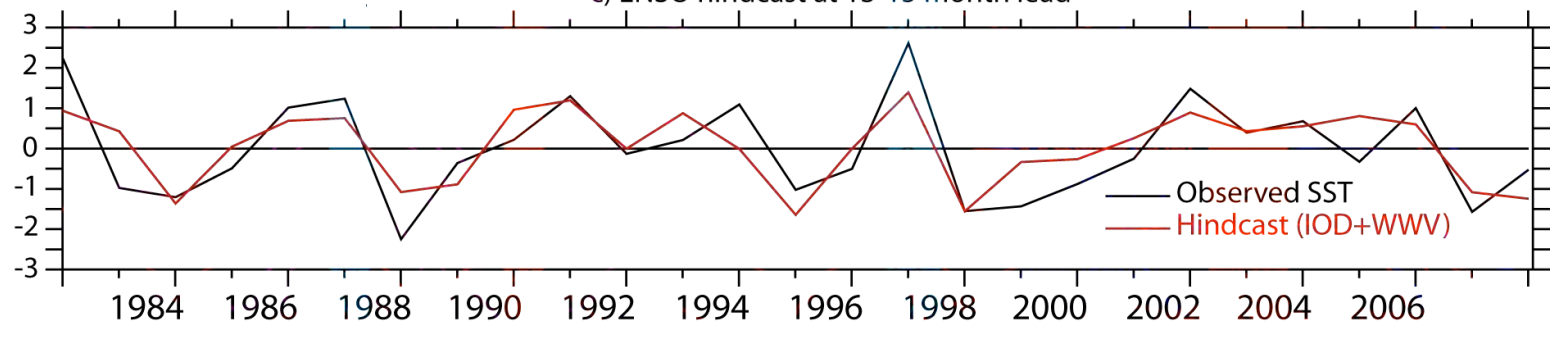

d) Contribution from IOD and WWV

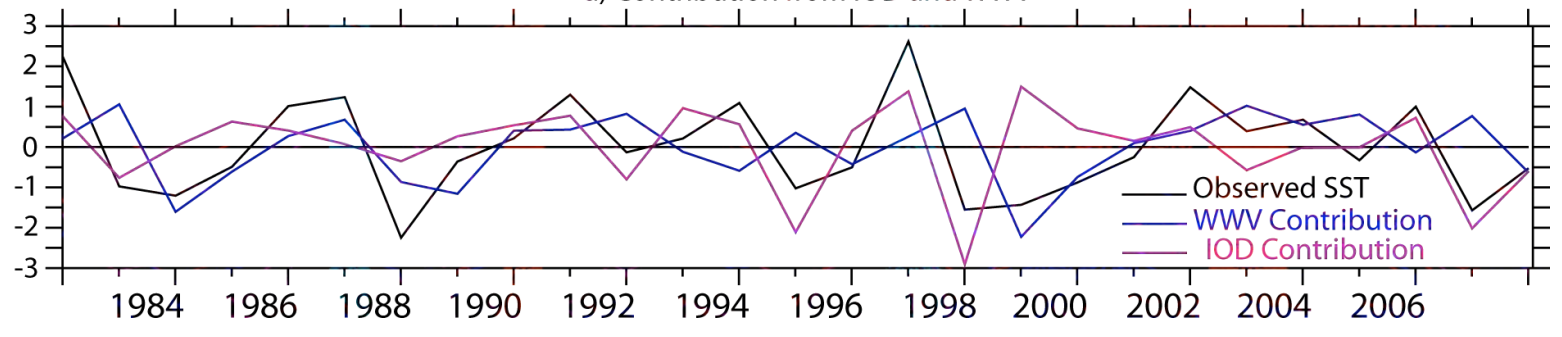

Figure 1. 


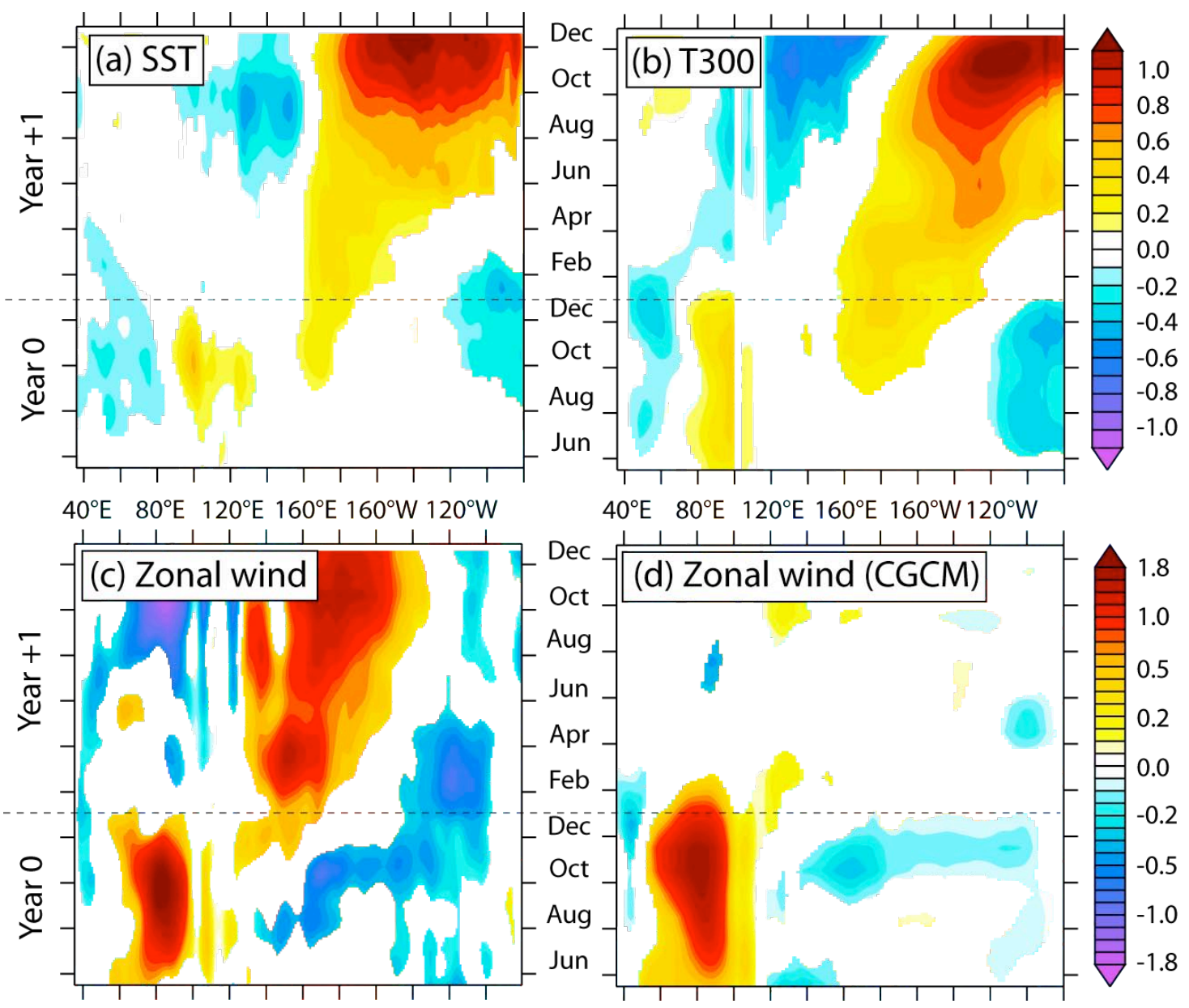

Figure 2. 


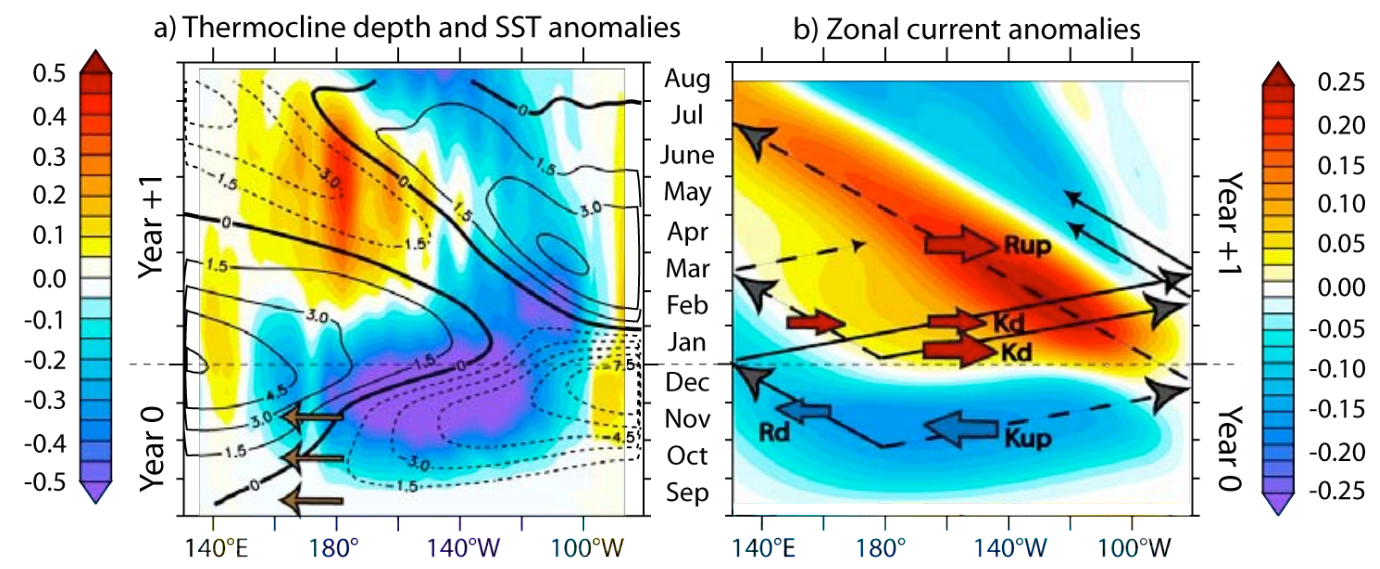

Figure 3. 


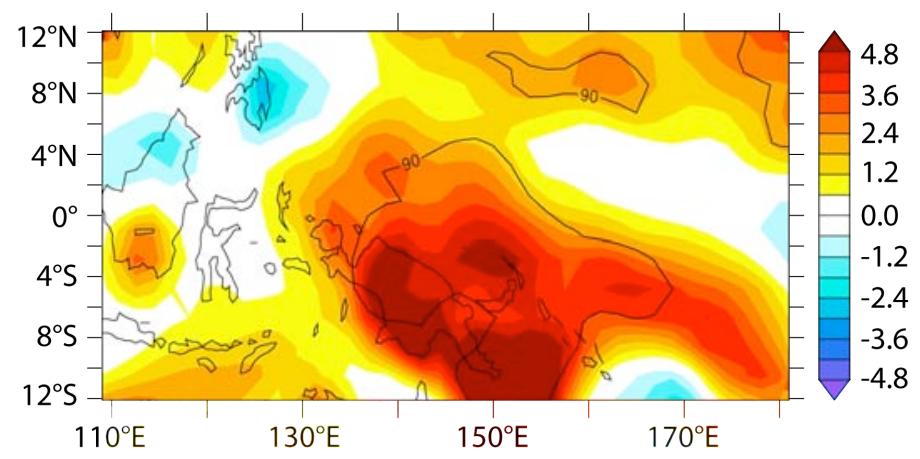

Figure 4. 